ISSN: 1808-8759

\title{
TEORES DE NUTRIENTES, VALORES ENERGÉTICOS E LEGALIDADE EM BEBIDAS NÃO-ALCOÓlICAS COMERCIAIS DE MANGA E DE GOIABA $^{1}$
}

\author{
Andressa Milene Parente Nogueira ${ }^{2} \&$ Waldemar Gastoni Venturini Filho ${ }^{3}$
}

RESUMO: O objetivo deste trabalho foi comparar os teores de nutrientes (carboidratos, proteínas e gorduras totais) e valores energéticos informados nos rótulos de bebidas não-alcoólicas comerciais de manga e de goiaba com os resultados encontrados em análises laboratoriais e padrões estabelecidos pela legislação brasileira. Dentre as bebidas de manga, foram analisadas quatro marcas de sucos tropicais não adoçados, três adoçados, seis néctares convencionais e três light. Dentre as de goiaba, quatro sucos tropicais não adoçados, três adoçados, cinco néctares convencionais e três light. Os teores de carboidratos, proteínas e gorduras totais foram obtidos através de análise química dessas bebidas, enquanto que os seus valores energéticos foram estimados através de cálculo centesimal, utilizando fatores de conversão para carboidratos $(4 \mathrm{kcal} / \mathrm{g})$, proteínas $(4 \mathrm{kcal} / \mathrm{g})$ e gorduras totais $(9 \mathrm{kcal} / \mathrm{g})$. As bebidas cujos teores de nutrientes e valores energéticos obtidos em laboratório excederam o intervalo de tolerância de $\pm 20 \%$, calculado a partir dos dados declarados em suas embalagens, foram consideradas fora dos padrões de qualidade. Das dezesseis bebidas comerciais de manga analisadas, metade declarou os teores de nutrientes e valores energéticos, em conjunto, de maneira correta em seus rótulos. Enquanto que, das quinze de goiaba, cinco puderam ser consideradas dentro dos padrões de qualidade.

PALAVRAS-CHAVE: Mangifera indica, Psidium guajava, rotulagem.

\section{NUTRIENTS CONTENTS, ENERGY VALUES, AND LEGALITY OF THE MANGO AND GUAVA NON- ALCOHOLIC BEVERADES COMMERCIAL}

\begin{abstract}
The objective of this research was to compare nutrients contents (carbohydrates, protein, and total fat) and energy values informed on the labels of commercial mango and guava non-alcoholic beverages with results found in laboratory tests and the standards established by Brazilian legislation. Among the mango beverages, four trademarks of unsweetened tropical juices, three sweetened, six conventional nectars, and three light were analyzed. Four guava unsweetened tropical juices, three sweetened, five conventional nectars, and three light were also analyzed. The carbohydrate, protein, and total fat contents were obtained by chemical analysis of these beverages, while their energy values were estimated by centesimal calculating, using conversion factors for carbohydrates (4kcal/g), protein $(4 \mathrm{kcal} / \mathrm{g})$, and total fat $(9 \mathrm{kcal} / \mathrm{g})$. The beverages that nutrients contents and energy values obtained in the laboratory exceeded the tolerance of $\pm 20 \%$, calculated from data informed in their packaging, were considered outside of quality standards. Of the sixteen commercial mango beverages analyzed, half had the nutrients contents and energy values together correctly declared on their labels. Of the fifteen of guava beverages, only five could be considered within the quality standards.
\end{abstract}

KEYWORDS: Mangifera indica, Psidium guajava, labeling.

\footnotetext{
${ }^{1}$ Parte da tese de doutorado do $1^{\circ}$ autor intitulada: Análise isotópica $\left(\delta^{13} \mathrm{C}\right)$, físico-química e energética de bebidas não-alcoólicas de manga (Mangifera indica, L.) e de goiaba (Psidium guajava, L.)

${ }^{2}$ Aluna do Programa de Pós-Graduação em Agronomia - Energia na Agricultura, FCA/UNESP - Botucatu/SP - Brasil, Bióloga, Fazenda Experimental Lageado. Rua José Barbosa de Barros, 1780. CEP:
}

18610-307. Caixa Postal 237. Telefone: + 55 (14) 3811-7103. E-mail: andressa_nogueira@yahoo.com.br

3 Orientador e docente do Departamento de Gestão e Tecnologia Agroindustrial, FCA/UNESP - Botucatu/SP - Brasil. E-mail: venturini@fca.unesp.br 


\section{INTRODUÇÃO}

Nos últimos anos, as vendas de frutas processadas na forma de sucos e néctares vêm aumentando significativamente no mercado brasileiro devido a diversas razões como melhora dos produtos oferecidos, praticidade, aumento da renda dos consumidores, valor nutritivo, bem como preocupação em adquirir alimentos mais saudáveis.

Para se ter uma idéia desse crescimento, segundo a Associação Brasileira das Indústrias de Refrigerantes e de Bebidas Não Alcoólicas (ABIR, 2012), em 2004, o volume de sucos e néctares de frutas vendidos no país foi de 253 milhões de litros, passando para 426 milhões em 2008. Os sucos e néctares de manga representaram 9,3\% desse total, sendo que os de goiaba participaram com $6,2 \%$.

Em 2010, o setor vendeu 533 milhões de litros, o equivalente a $20 \%$ a mais em relação a 2008. O maior consumidor foi o interior do Estado de São Paulo, com $24 \%$ desse total, o que representou um consumo per capita de 5,90 litros/ano (ABRIR, 2012).

No entanto, muitos consumidores não sabem diferenciar suco de néctar, sendo o conjunto dessas bebidas denominado por grande parte das pessoas apenas por "suco".

O suco de fruta propriamente dito é apenas aquele que apresenta $100 \%$ de suco de fruta em sua composição, salvo as exceções de frutas muito viscosas que necessitam de diluição do seu suco ou polpa (parte carnuda das frutas), como é o caso da manga e da goiaba (PIRILLO e SABIO, 2009). Quando isso ocorre, tratando-se de fruta de origem tropical, então a bebida passa a ser denominada de suco tropical, conforme a legislação brasileira (BRASIL, 2009).

O suco tropical pode ser adicionado de açúcar. Neste caso, a bebida deverá ser denominada de suco tropical, acrescido do nome da fruta e da designação adoçado, podendo ser declarado no rótulo a expressão suco pronto para beber, pronto para o consumo ou expressões semelhantes (BRASIL 2009).

É vedada a designação de suco tropical a bebida que não necessite de água na sua elaboração e que não seja proveniente de fruta de origem tropical (BRASIL, 2003a).

Os teores de polpa de frutas utilizados na elaboração do suco tropical deverão ser superiores aos estabelecidos para o néctar das respectivas frutas (BRASIL, 2009).

Quanto menor a quantidade de polpa de fruta presente na bebida, menor seu preço. Como este é um fator importante na decisão de compra, o néctar de fruta vem ganhando espaço entre os consumidores. Além da questão do preço, um estudo realizado por Ferrarezi (2008), o qual analisou o comportamento de consumidores de sucos e néctares de laranja em
Araraquara (SP), mostrou que as pessoas reagiram mais positivamente ao termo "néctar", associando a palavra a um produto "puro", "mais puro" ou que continha "a melhor parte da fruta", exatamente o contrário do que está descrito na legislação brasileira.

Nos rótulos dessas bebidas, a declaração dos teores de nutrientes e valores energéticos, além de obrigatória, deve ser apresentada claramente para facilitar sua livre circulação, evitar obstáculos técnicos ao comércio e, principalmente, atuar em benefício do consumidor. Neste sentido, o Código de Proteção e Defesa do Consumidor garante que diferentes produtos devem trazer informações claras e adequadas com especificação correta de sua composição, características e qualidade (BRASIL, 1990).

Em relação aos teores de nutrientes (carboidratos, proteínas e gorduras totais), a lei define que valores inferiores a $10 \mathrm{~g} / 200 \mathrm{~mL}$ devem ser expressos com uma cifra decimal, valores iguais ou maiores que $10 \mathrm{~g} / 200 \mathrm{~mL}$ e menores que $100 \mathrm{~g} / 200 \mathrm{~mL}$ devem ser expressos em números inteiros com duas cifras e valores iguais ou maiores que $100 \mathrm{~g} / 200 \mathrm{~mL}$ devem ser expressos inteiros com três cifras (BRASIL, 2003b).

A legislação brasileira também determina que o valor energético de alimentos deve ser expresso nas unidades kcal e kJ, representadas lado a lado, e declarados em números inteiros (BRASIL, 2003b). A unidade padrão utilizada pelo Sistema Internacional de Medidas (SI) para expressar o valor energético é o Joule (J), que é a energia gasta para movimentar $1 \mathrm{~kg}$ pela distância de $1 \mathrm{~m}$ utilizando uma força de 1 Newton. Porém, por muitas décadas, a energia de alimentos tem sido expressa em caloria, a qual corresponde à quantidade de energia necessária para elevar a temperatura de $1 \mathrm{~g}$ de água em $1^{\circ} \mathrm{C}$, mais precisamente, de $14,5^{\circ} \mathrm{C}$ para $15,5^{\circ} \mathrm{C}$. Uma caloria corresponde a 4,186 Joule (ROZENBERG, 2002; TACO, 2004).

A informação nutricional será expressa como "zero" ou "0" ou "não contém" para teor de nutrientes quando a bebida contiver quantidade menor ou igual a $0,5 \mathrm{~g} / 200 \mathrm{~mL}$ e o valor energético quando for menor ou igual a $4 \mathrm{kcal}$ ou $17 \mathrm{~kJ}$ (BRASIL, 2003b).

É permitida uma variação de $20 \%$, para mais ou para menos, nos teores de nutrientes e valores energéticos informados nos rótulos dos produtos (BRASIL, 2003b).

Com base nessas informações, o objetivo deste trabalho foi comparar os teores de nutrientes (carboidratos, proteínas e gorduras totais) e valores energéticos informados nos rótulos de bebidas não-alcoólicas comerciais de manga e de goiaba com os resultados encontrados em análises laboratoriais e padrões estabelecidos pela legislação brasileira. 


\section{MATERIAL E MÉTODOS}

\subsection{Amostras}

Foram compradas quatro marcas de sucos tropicais não adoçados, três adoçados, seis néctares convencionais e três light de manga em supermercados de Botucatu/SP, no primeiro semestre de 2010. Também foram adquiridas quatro marcas de sucos tropicais não adoçados, três adoçados, cinco néctares convencionais e três light de goiaba.

Todas as bebidas foram obtidas em triplicata, cada embalagem representando uma repetição, com o mesmo número de lote e dentro do prazo de validade.

Cada marca recebeu um número diferente para manter a idoneidade de seus fabricantes.

\subsection{Métodos}

Os teores de nutrientes (carboidratos, proteínas e gorduras totais) foram determinados através de análise da composição centesimal das bebidas. Em seguida, seus valores energéticos foram mensurados de forma indireta por cálculo centesimal.

\subsubsection{Teores de nutrientes $(\%)$}

A composição centesimal incluiu a determinação do teor de umidade, cinzas, gorduras totais, proteínas e carboidratos. Todos os parâmetros foram determinados segundo metodologia descrita por Brasil (2005), com exceção do teor de gorduras totais, baseado no método de Bligh e Dyer (1959).

- Umidade: determinada pelo método de secagem em estufa, através da perda de peso da amostra aquecida a $105 \pm 1^{\circ} \mathrm{C}$, até peso constante.

- Cinzas: determinada pela incineração da matéria orgânica e posterior calcinação das amostras em mufla a $550^{\circ} \mathrm{C}$.

- Gorduras totais: obtida pela mistura a frio da amostra com metanol, clorofórmio e água formando apenas uma fase. Depois mais clorofórmio é adicionado, juntamente com solução de sulfato de sódio 1,5\%, estabelecendo-se assim duas fases. A gordura fica na fase do clorofórmio (camada inferior), sendo recuperada e evaporada em estufa a $105^{\circ} \mathrm{C}$, até peso constante.

- Proteínas: calculada a partir dos teores de nitrogênio total, usando fator de conversão de 6,25. O nitrogênio total foi determinado pelo método Kjeldahl.

- Carboidratos: calculado pela diferença entre 100 e a soma das porcentagens de umidade, proteínas, gorduras totais e cinzas.

\subsubsection{Valor energético (kcal e kJ)}

Após a determinação da composição centesimal, o valor energético de cada bebida foi calculado a partir dos teores de carboidratos, proteínas e gorduras totais, utilizando fatores de conversão de $4 ; 4$ e $9 \mathrm{kcal} / \mathrm{g}$, respectivamente (ATWATER \& BENEDICT, 1902 apud FAO, 2003).
Nos rótulos dessas bebidas, os valores energéticos são declarados em $\mathrm{kcal} / 200 \mathrm{~mL}$. Por isso, os resultados obtidos através do cálculo centesimal, expressos em $\mathrm{kcal} / 100 \mathrm{~g}$, foram transformados em $\mathrm{kcal} / 200 \mathrm{~mL} \mathrm{em}$ função do teor de sólidos solúveis e da densidade de cada amostra, possibilitando a comparação entre os valores obtidos nas análises laboratoriais com os informados nos rótulos dos produtos. Os valores obtidos em kcal foram convertidos para $\mathrm{kJ}$ ( $1 \mathrm{kcal}$ equivale a aproximadamente $4,2 \mathrm{~kJ}$ ).

\subsubsection{Comparação entre os rótulos das bebidas comerciais e a legislação brasileira}

As bebidas de manga e de goiaba cujos teores de nutrientes e valores energéticos obtidos em laboratório extrapolaram o intervalo de tolerância de $\pm 20 \%$ estabelecido por lei, calculado a partir dos dados declarados em seus rótulos, foram consideradas fora dos padrões de qualidade (BRASIL, 2003b).

\section{RESULTADOS E DISCUSSÃO}

\subsection{Bebidas de manga}

A Tabela1 mostra os resultados dos teores de nutrientes (carboidratos, proteínas e gorduras totais) obtidos para as bebidas comerciais de manga.

\begin{tabular}{|c|c|c|c|c|c|c|c|c|c|c|c|c|}
\hline \multirow[t]{4}{*}{ Tab } & elc & & \multicolumn{4}{|c|}{$\begin{array}{l}\text { Comparação } \\
\text { carboidratos, } \\
\text { totais informa } \\
\text { bebidas come } \\
\text { obtidos na an }\end{array}$} & & 0 & 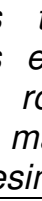 & $\begin{array}{l}\text { gores } \\
\text { ulos } \\
\text { nga } \\
\text { al. }\end{array}$ & $\begin{array}{c}d e \\
\text { ura }\end{array}$ & \\
\hline & \multicolumn{12}{|c|}{ Valores referentes a $200 \mathrm{~mL}$ de bebida de manga } \\
\hline & \multicolumn{4}{|c|}{ Carboidratos } & \multicolumn{4}{|c|}{ Proteínas } & \multicolumn{4}{|c|}{ Gorduras totais } \\
\hline & RT & $\begin{array}{r}+20 \\
\%^{1}\end{array}$ & $\begin{array}{c}-20 \\
\%\end{array}$ & $\begin{array}{l}\mathbf{A} \\
\mathbf{C}\end{array}$ & RT & $\begin{array}{c}+20 \\
\%\end{array}$ & $\begin{array}{c}-20 \\
\%\end{array}$ & $\begin{array}{l}\mathbf{A} \\
\mathbf{C}\end{array}$ & RT & $\begin{array}{c}+20 \\
\%\end{array}$ & $\overline{20 \%}$ & $\begin{array}{l}\mathbf{A} \\
\mathbf{C}\end{array}$ \\
\hline \multicolumn{13}{|c|}{$\begin{array}{ll}1.3 & \begin{array}{l}\text { Sucos tropicais não } \\
\text { adoçados }\end{array}\end{array}$} \\
\hline 11 & 40 & 48 & 32 & 19 & --- & --- & --- & 0,6 & --- & --- & --- & 0,7 \\
\hline 12 & 24 & 28,8 & 19,2 & 18 & --- & --- & --- & 0,7 & --- & --- & --- & 0,5 \\
\hline 13 & 23 & 27,6 & 18,4 & 16 & --- & --- & --- & 0,6 & 0 & 0 & 0 & 0,7 \\
\hline 97 & 20 & 24,0 & 16,0 & 20 & --- & --- & --- & 0,7 & --- & --- & --- & 0,2 \\
\hline \multicolumn{13}{|c|}{ Sucos tropicais adoçados } \\
\hline 94 & 27 & 32,4 & 21,6 & 24 & 0 & 0 & 0 & $\overline{0,4}$ & 0 & 0 & 0 & 0,5 \\
\hline 95 & 20 & 24,0 & 16,0 & 21 & 0 & 0 & 0 & 0,4 & 0 & 0 & 0 & 0,4 \\
\hline 98 & 27 & 32,4 & 21,6 & 21 & 0 & 0 & 0 & 0,4 & 0 & 0 & 0 & 0,1 \\
\hline \multicolumn{13}{|c|}{ Néctares convencionais } \\
\hline 4 & 28 & 33,6 & 22,4 & 26 & --- & --- & --- & 0,6 & --- & --- & --- & 0,3 \\
\hline 5 & 26 & 31,2 & 20,8 & 23 & 0 & 0 & 0 & 0,3 & 0 & 0 & 0 & 0,8 \\
\hline 6 & 26 & 31,2 & 20,8 & 22 & 0 & 0 & 0 & 0,4 & 0 & 0 & 0 & 0,5 \\
\hline 7 & 25 & 30,0 & 20,0 & 22 & 0 & 0 & 0 & 0,4 & 0 & 0 & 0 & 0,4 \\
\hline 8 & 24 & 28,8 & 19,2 & 22 & -- & --- & -- & 0,4 & --- & --- & --- & 0,6 \\
\hline 93 & 24 & 28,8 & 19,2 & 24 & --- & --- & --- & 0,5 & --- & --- & --- & 0,4 \\
\hline \multicolumn{13}{|c|}{ Néctares light } \\
\hline 9 & 7,6 & 9,1 & 6,1 & 7,0 & 0 & 0 & 0 & 0,5 & 1,1 & 1,32 & 0,88 & 0,9 \\
\hline 10 & 7,6 & 9,1 & 6,1 & 6,5 & -- & --- & -- & 0,4 & --- & --- & --- & 0,3 \\
\hline 96 & 7,6 & 9,1 & 6,1 & 8,3 & --- & --- & --- & 0,4 & --- & --- & --- & 0,5 \\
\hline
\end{tabular}

${ }^{1}$ Tolerância de variação de $\pm 20 \%$ calculada sobre os teores de carboidratos, proteínas e gorduras totais declarados nos rótulos das bebidas comerciais de manga; $\mathrm{RT}=$ Rótulo das bebidas comerciais; $\mathrm{AC}=$ Análise centesimal.

Todas as marcas de sucos tropicais adoçados, néctares convencionais e light corresponderam à possibilidade de 
variação de $\pm 20 \%$ e à declaração dos números quanto às cifras decimais nos valores de carboidratos informados em suas embalagens. Dentre os sucos tropicais não adoçados, somente a amostra 97 respeitou a faixa de variação, sendo que as demais amostras apresentaram valores de carboidratos superestimados em seus rótulos.

Todos os sucos tropicais não adoçados apresentaram a indicação da quantidade de proteínas em seus rótulos de maneira incorreta. Como seus valores na análise laboratorial variaram entre 0,6 e $0,7 \mathrm{~g} / 200 \mathrm{~mL}$, eles deveriam ter sido expressos com uma cifra decimal. A indicação da quantidade desse componente nas embalagens só pode ser nula quando a quantidade de proteínas for igual ou menor a $0,5 \mathrm{~g} / 200 \mathrm{~mL}$ (BRASIL, 2003b), o que não correspondeu aos resultados obtidos. Este fato também foi observado para amostra 4 (néctar convencional). As demais bebidas estavam de acordo com os padrões de qualidade estabelecidos por lei quanto ao teor de proteínas.

Assim como discutido para o teor de proteínas, a informação de gorduras totais nos rótulos das bebidas somente poderá ser expressa de maneira nula quando esta contiver quantidade menor ou igual a $0,5 \mathrm{~g} / 200 \mathrm{~mL}$ (BRASIL, 2003b). Dessa forma, duas marcas de sucos tropicais não adoçados (amostras 11 e 13) e duas de néctares convencionais (amostras 5 e 8) não respeitaram as determinações da lei. Vale destacar que a indicação da quantidade de gorduras totais no rótulo da amostra 9 (néctar light) foi correta, pois valores maiores que $0,5 \mathrm{~g} / 200 \mathrm{~mL}$ devem ser expressos com uma cifra decimal, de acordo com Brasil (2003b). As demais bebidas estavam de acordo com a legislação brasileira.

De maneira geral, considerando-se todos os resultados referentes aos teores de nutrientes foi possível averiguar que, dentre as quatro amostras de sucos tropicais não adoçados, somente a amostra 97 foi considerada dentro dos padrões de qualidade considerando-se todos os componentes analisados. Dentre as seis de néctares convencionais, metade (amostras 6, 7 e 93) teve essa mesma classificação, bem como todas as de sucos tropicais adoçados e néctares light.

Na Tabela 2, os valores energéticos expressos nos rótulos das bebidas comerciais de manga foram comparados com os resultados estimados por cálculo centesimal.
Tabela 2: Comparação entre os valores energéticos informados nos rótulos das bebidas comerciais de manga $e$ os estimados pelo cálculo centesimal.

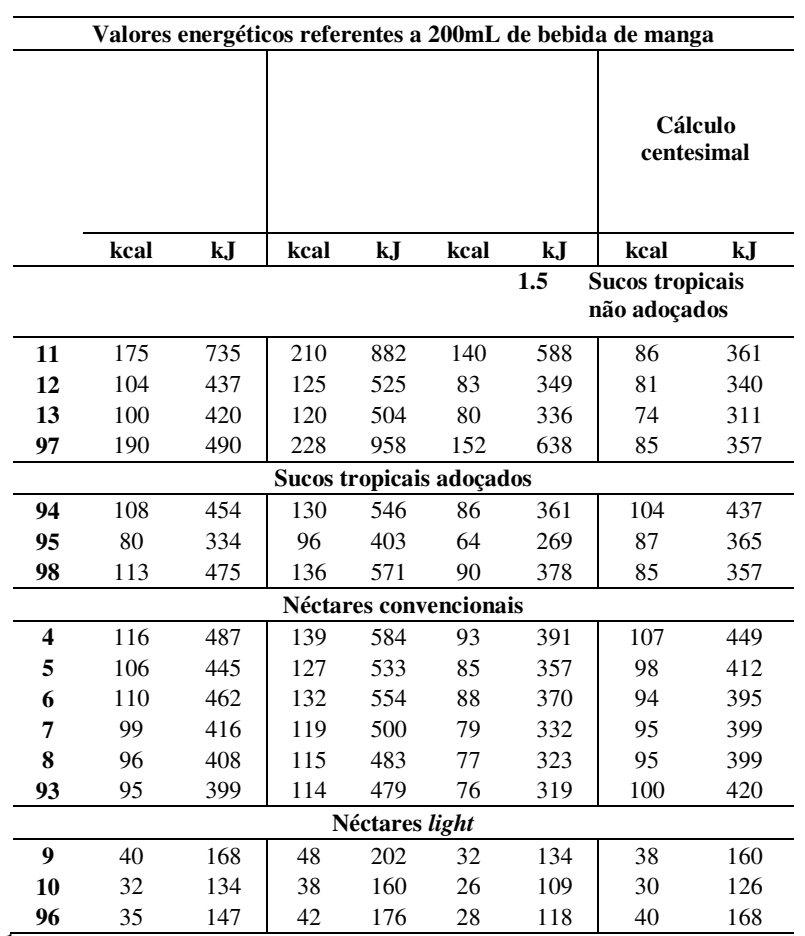

Tolerância de variação de $\pm 20 \%$ calculada sobre os valores energéticos declarados nos rótulos das bebidas comerciais de manga.

Nela, foi possível observar que todos os sucos tropicais não adoçados tiveram seus valores energéticos superestimados em seus rótulos. O maior problema em superestimar os valores energéticos nos rótulos de produtos é que estes podem ser prejudiciais para pessoas que necessitam de uma maior ingestão de calorias como, por exemplo, atletas e gestantes. Dentre os sucos tropicais adoçados, a amostra 98 teve seu valor energético superestimado no rótulo. As outras duas marcas de sucos tropicais adoçados e todas as de néctares convencionais e light estavam de acordo com a lei.

A amostra 97 (suco tropical não adoçado) apresentou seu valor energético expresso em $\mathrm{kJ}$ abaixo do real. O valor encontrado no rótulo desta bebida foi de $490 \mathrm{~kJ}$, quando, na verdade, deveria ser de $798 \mathrm{~kJ}$.

Quando os rótulos das amostras foram estudados unindose os resultados obtidos para os teores de nutrientes e valores energéticos, de maneira geral, constatou-se que, das quatro amostras de sucos tropicais não adoçados analisadas, nenhuma pôde ser considerada dentro dos padrões de qualidade. Dos três sucos tropicais adoçados, dois obedeceram às determinações da lei (amostras 94 e 95), assim como três dos seis néctares convencionais (amostras 6, 7 e 93) e todos os três néctares light. 
Ou seja, das dezesseis bebidas comerciais de manga analisadas, metade declarou os teores de nutrientes e valores energéticos em seus rótulos de maneira correta. A outra metade declarou valores incoerentes em um ou mais componentes analisados.

\subsection{Bebidas de goiaba}

A Tabela 3 mostra os resultados dos teores de nutrientes (carboidratos, proteínas e gorduras totais) obtidos para as bebidas comerciais de goiaba.

Tabela 3: Comparação entre os teores de carboidratos, proteínas e gorduras totais informados nos rótulos das bebidas comerciais de goiaba e os obtidos na análise centesimal.

\begin{tabular}{|c|c|c|c|c|c|c|c|c|c|c|c|c|}
\hline \multicolumn{13}{|c|}{ Valores referentes a $200 \mathrm{~mL}$ de bebida de goiaba } \\
\hline & \multicolumn{4}{|c|}{ Carboidratos } & \multicolumn{4}{|c|}{ Proteínas } & \multicolumn{4}{|c|}{ Gorduras totais } \\
\hline & $\begin{array}{l}\mathbf{R} \\
\mathbf{T} \\
\end{array}$ & $\begin{array}{c}+20 \\
\%^{1}\end{array}$ & $\begin{array}{c}-20 \\
\%\end{array}$ & $\begin{array}{l}\mathbf{A} \\
\mathbf{C}\end{array}$ & $\begin{array}{l}\mathbf{R} \\
\mathbf{T}\end{array}$ & $\begin{array}{c}+20 \\
\%\end{array}$ & $\begin{array}{c}-20 \\
\%\end{array}$ & $\begin{array}{l}\mathbf{A} \\
\mathbf{C}\end{array}$ & $\begin{array}{l}\mathbf{R} \\
\mathbf{T} \\
\end{array}$ & $\begin{array}{c}+20 \\
\%\end{array}$ & $\begin{array}{c}-20 \\
\%\end{array}$ & $\begin{array}{l}\mathbf{A} \\
\mathbf{C}\end{array}$ \\
\hline \multicolumn{13}{|c|}{1.3} \\
\hline 162 & 22 & 26,4 & 17,6 & 11 & --- & --- & --- & 0,8 & --- & --- & --- & 0,3 \\
\hline 163 & 30 & 36,0 & 24,0 & 12 & --- & --- & --- & 0,8 & --- & --- & --- & 0,0 \\
\hline 164 & 10 & 12,0 & 8,0 & 9,2 & --- & --- & --- & 0,6 & --- & --- & --- & 1,1 \\
\hline 165 & 10 & 12,0 & 8,0 & 11 & --- & --- & --- & 0,7 & --- & --- & --- & 0,4 \\
\hline \multicolumn{13}{|c|}{ Sucos tropicais adoçados } \\
\hline 160 & 25 & 30,0 & 20,0 & 23 & 0,7 & 0,8 & 0,6 & 0,3 & 0 & 0 & 0 & 0,3 \\
\hline 161 & 23 & 27,6 & 18,4 & 22 & 0 & 0 & 0 & 0,3 & 0 & 0 & 0 & 0,4 \\
\hline 173 & 19 & 22,8 & 15,2 & 22 & 0 & 0 & 0 & 0,3 & 0 & 0 & 0 & 0,1 \\
\hline \multicolumn{13}{|c|}{ Néctares convencionais } \\
\hline 14 & 26 & 31,2 & 20,8 & 24 & --- & --- & --- & 0,4 & --- & --- & --- & 0,3 \\
\hline 15 & 25 & 30,0 & 20,0 & 23 & 0 & 0 & 0 & 0,5 & 0,8 & 1,0 & 0,6 & 0,5 \\
\hline 154 & 24 & 28,8 & 19,2 & 20 & 0,7 & 0,8 & 0,6 & 0,5 & 0 & 0 & 0 & 0,4 \\
\hline 155 & 21 & 25,2 & 16,8 & 23 & 0 & 0 & 0 & 0,5 & 0 & 0 & 0 & 0,4 \\
\hline 156 & 21 & 25,2 & 16,8 & 20 & --- & --- & --- & 0,6 & -- & --- & --- & 0,4 \\
\hline \multicolumn{13}{|c|}{ Néctares light } \\
\hline 157 & 4,8 & 5,8 & 3,8 & 5,0 & 0 & 0 & 0 & 0,5 & 0 & 0 & 0 & 0,2 \\
\hline 158 & 4,8 & 5,8 & 3,8 & 6,8 & --- & --- & --- & 0,5 & --- & --- & --- & 0,9 \\
\hline 159 & 6,0 & 7,2 & 4,8 & 5,8 & 0,7 & 0,8 & 0,6 & 0,4 & 0 & 0 & 0 & 0,2 \\
\hline
\end{tabular}

1 Tolerância de variação de $\pm 20 \%$ calculada sobre os teores de carboidratos, proteínas e gorduras totais declarados nos rótulos das bebidas comerciais de goiaba; $\mathrm{RT}=$ Rótulo das bebidas comerciais; $\mathrm{AC}=$ Análise centesimal

Dentre as quatro marcas de sucos tropicais não adoçados, metade respeitou a variação de $\pm 20 \%$ para o teor de carboidratos (amostras 164 e 165). As demais amostras de sucos tropicais não adoçados apresentaram valores abaixo do limite de variação. Todas as marcas de sucos tropicais adoçados e néctares convencionais respeitaram o limite de variação $\pm 20 \%$, bem como à declaração dos números quanto às cifras decimais. Nos néctares light, a amostra 158 subestimou os teores de carboidratos em seu rótulo.
Novamente, assim como ocorreu para os sucos tropicais não adoçados de manga, todos os de goiaba apresentaram a indicação da quantidade de proteínas em seus rótulos de maneira incorreta. $\mathrm{Na}$ análise laboratorial, foram encontrados valores de 0,6 a $0,8 \mathrm{~g}$ de proteínas $/ 200 \mathrm{~mL}$ de suco. Como explicado anteriormente, tais valores deveriam ter sido expressos nos rótulos dos produtos com uma cifra decimal ao invés da expressão nula. Isso também ocorreu com a amostra 156 (néctar convencional). Por outro lado, o contrário foi observado para as amostras 160 (suco tropical adoçado), 154 (néctar convencional) e 159 (néctar light). Seus rótulos apresentaram valores de proteínas acima de $0,5 \mathrm{~g} / 200 \mathrm{~mL}$, quando na realidade ficaram abaixo deste valor. Ou seja, em seus rótulos, o teor de proteínas deveria ter sido expresso como "zero", "0" ou "não contém". As demais bebidas estavam de acordo com os padrões de qualidade estabelecidos por lei quanto ao teor de proteínas.

Uma marca de suco tropical não adoçado (amostra 164) e uma de néctar light (amostra 158) não respeitaram as determinações da lei, pois apresentaram em seus rótulos valores subestimados de gorduras totais. A análise laboratorial mostrou resultados de 1,1 e $0,9 \mathrm{~g} / 200 \mathrm{~mL}$, respectivamente. A declaração de gorduras totais em seus rótulos foi nula. Isso somente poderia ocorrer se os valores obtidos em laboratório fossem igual ou menor a $0,5 \mathrm{~g} / 200 \mathrm{~mL}$. O oposto aconteceu com a amostra 15 (néctar convencional), apresentando valor superestimado de gorduras totais em seu rótulo. Os outros produtos foram considerados dentro dos padrões de qualidade em relação ao teor de gorduras totais.

Analisando-se todos os resultados obtidos para os teores de nutrientes foi possível verificar que, dentre as quatro amostras de sucos tropicais não adoçados nenhuma foi considerada dentro dos padrões de qualidade para os teores de carboidratos, proteínas e gorduras totais, em conjunto. Dentre as três marcas de sucos tropicais adoçados, uma teve essa mesma classificação (amostra 160), da mesma forma que três dos cinco néctares convencionais (amostras 15, 154 e 156) e dois dos três néctares light (amostras 158 e 159).

$\mathrm{Na}$ Tabela 4, os valores energéticos expressos nos rótulos das bebidas comerciais de goiaba foram comparados com os resultados estimados por cálculo centesimal. 
Tabela 4: Comparação entre os valores energéticos informados nos rótulos das bebidas comerciais de goiaba $e$ os estimados pelo cálculo centesimal.

\begin{tabular}{|c|c|c|c|c|c|c|c|c|}
\hline \multicolumn{9}{|c|}{ Valores energéticos referentes à $200 \mathrm{~mL}$ de bebida de goiaba } \\
\hline & \multirow[b]{2}{*}{ kcal } & \multirow[b]{2}{*}{ kJ } & \multirow[b]{2}{*}{ kcal } & \multirow[b]{2}{*}{ kJ } & \multirow[b]{2}{*}{ kcal } & \multirow[b]{2}{*}{ kJ } & \multicolumn{2}{|c|}{$\begin{array}{l}\text { Cálculo } \\
\text { centesimal }\end{array}$} \\
\hline & & & & & & & kcal & kJ \\
\hline & & & & & 1.7 & \multicolumn{3}{|c|}{$\begin{array}{l}\text { Sucos tropicais não } \\
\text { adoçados }\end{array}$} \\
\hline 162 & 96 & 403 & 115 & 483 & 77 & 323 & 51 & 214 \\
\hline 163 & 110 & 420 & 132 & 554 & 88 & 370 & 52 & 218 \\
\hline 164 & 48 & --- & 58 & --- & 38 & --- & 49 & --- \\
\hline 165 & 50 & 210 & 60 & 252 & 40 & 168 & 49 & 206 \\
\hline \multicolumn{9}{|c|}{ Sucos tropicais adoçados } \\
\hline 160 & 103 & 433 & 124 & 521 & 82 & 344 & 96 & 403 \\
\hline 161 & 97 & 405 & 116 & 487 & 78 & 328 & 92 & 386 \\
\hline 173 & 80 & 333 & 96 & 403 & 64 & 269 & 91 & 382 \\
\hline \multicolumn{9}{|c|}{ Néctares convencionais } \\
\hline 14 & 104 & 438 & 125 & 525 & 83 & 349 & 101 & 424 \\
\hline 15 & 108 & 454 & 130 & 546 & 86 & 361 & 99 & 416 \\
\hline 154 & 101 & 424 & 121 & 508 & 81 & 340 & 87 & 365 \\
\hline 155 & 89 & 374 & 107 & 449 & 71 & 298 & 95 & 399 \\
\hline 156 & 84 & 357 & 101 & 424 & 67 & 281 & 87 & 365 \\
\hline \multicolumn{9}{|c|}{ Néctares light } \\
\hline 157 & 20 & 84 & 24 & 101 & 16 & 67 & 24 & 101 \\
\hline 158 & 21 & 88 & 25 & 105 & 17 & 71 & 37 & 155 \\
\hline 159 & 26 & 109 & 31 & 130 & 21 & 88 & 26 & 109 \\
\hline
\end{tabular}

1 Tolerância de variação de $\pm 20 \%$ calculada sobre os valores energéticos declarados nos rótulos das bebidas comerciais de goiaba.

Metade dos sucos tropicais não adoçados teve seu valor energético superestimado em seus rótulos (amostras 162 e 163). A amostra 164 respeitou o limite de tolerância de $\pm 20 \%$, no entanto, apresentou seu valor energético somente em kcal. Todos os sucos tropicais não adoçados e néctares convencionais obedeceram ao intervalo de tolerância de $20 \%$ para mais ou menos. Dentre os três néctares light, a amostra 158 teve seu valor energético subestimado no rótulo. Produtos com valores energéticos subestimados podem ser prejudicais para pessoas que possuem dietas de baixa ingestão calórica.

Quando os rótulos das amostras de goiaba foram estudados unindo-se os resultados obtidos para os teores de nutrientes e valores energéticos, observou-se que, das quatro amostras de sucos tropicais não adoçados analisadas, nenhuma pôde ser considerada dentro dos padrões de qualidade. Dos três sucos tropicais adoçados, dois obedeceram às determinações da lei (amostras $161 \mathrm{e}$ 173), assim como dois dos cinco néctares convencionais (amostras 14 e 155) e um dos três néctares light (amostra 157).
Portanto, das quinze bebidas comerciais de goiaba analisadas, cinco declaram os teores de nutrientes e valores energéticos em seus rótulos de maneira correta. As outras dez, ou seja, a maioria declarou valores incoerentes em um ou mais componentes analisados.

\section{CONCLUSÃO}

Das dezesseis bebidas comerciais de manga analisadas, metade declarou os teores de nutrientes e valores energéticos, em conjunto, de maneira correta em seus rótulos. Enquanto que, das quinze de goiaba, cinco puderam ser consideradas dentro dos padrões de qualidade.

\section{AGRADECIMENTOS}

À Fundação de Amparo à Pesquisa do Estado de São Paulo (FAPESP - processo $\mathrm{n}^{\circ}$ 2009/53974-7) e Coordenação de Aperfeiçoamento de Pessoal de Nível Superior (CAPES).

\section{REFERÊNCIAS}

\section{ASSOCIAÇÃO BRASILEIRA DAS INDÚSTRIAS DE} REFRIGERANTES E DE BEBIDAS NÃO

ALCOÓLICAS. O setor. Brasília, DF, 2011. Disponível em: <http://abir.org.br/categoria/o-setor/>. Acesso em: 05 jan. 2012.

BLIGH, E. G.; DYER, W. J. A rapid method for total lipid extraction and purification. Canadian Journal of Biochemistry and Physiology, v. 37, n. 8, p. 911-917, 1959.

BRASIL. Código de Proteção e Defesa do Consumidor. Lei n. 8.078, de 11 de setembro de 1990. Dispõe sobre a proteção do consumidor e dá outras providências. Diário Oficial da União, Brasília, DF, 15 set. 1990. Disponível em:

<http://www.planalto.gov.br/ccivil_03/leis/L8078.htm>. Acesso em: 15 jan. 2012.

BRASIL. Ministério da Agricultura, Pecuária e Abastecimento. Instrução Normativa n. 12, de 04 de setembro de 2003a. Aprova o Regulamento Técnico para Fixação dos Padrões de Identidade e Qualidade Gerais para Suco Tropical e Néctar. Diário Oficial da União, Brasília, DF, 09 set. 2003. Disponível em: $<$ http://extranet.agricultura.gov.br/sislegisconsulta/consultarLegislacao.do?operacao=visualizar\&id $=2831$ > . Acesso em: 05 jan. 2012.

BRASIL. Ministério da Saúde. Agência Nacional de Vigilância Sanitária. Resolução RDC n. 360, de 23 de dezembro de 2003b. Aprova o regulamento técnico sobre rotulagem nutricional de alimentos embalados, tornando obrigatória a rotulagem nutricional. Diário Oficial da União, Brasília, DF, 26 dez. 2003. Disponível em: $<\mathrm{http} / / /$ www.anvisa.gov.br/legis/resol/2003/rdc/360_03r dc.htm>. Acesso em: 15 jan. 2012. 
BRASIL. Ministério da Saúde. Agência Nacional de Vigilância Sanitária. Métodos físico-químicos para análise de alimentos. 4. ed. Brasília, DF, 2005. 1018 p.

BRASIL. Ministério da Agricultura, Pecuária e Abastecimento. Decreto n. 6.871, de 04 de junho de 2009. Regulamenta a Lei n. 8.918, de 14 de julho de 1994, que dispõe sobre a padronização, a classificação, o registro, a inspeção, a produção e a fiscalização de bebidas. Diário Oficial da União, Brasília, DF, 05 jun. 2009b. Disponível em: $<$ http://extranet.agricultura.gov.br/sislegisconsulta/consultarLegislacao.do?operacao=visualizar\&id =20271>. Acesso em: 05 jan. 2012 .

FERRAREZI, A. C. Interpretação do consumidor, avaliação da intenção de compra e das características físico-químicas do néctar e do suco de laranja pronto para beber. 2008. 104 f. Dissertação (Mestrado em Alimentos e Nutrição/Ciência dos Alimentos)-Faculdade de Ciências Farmacêuticas, Universidade Estadual Paulista, Araraquara, 2008.

FOOD AND AGRICULTURE ORGANIZATION. Food energy: methods of analysis and conversion factors. Rome, 2003. 87 p. (Report of a Technical Workshop).

PIRILLO, C. P; SABIO, R. P. 100\% suco: nem tudo é suco nas bebidas de frutas. Hortifruti Brasil, Piracicaba, v. 8, n. 81, p. 6-13, 2009.

ROZENBERG, I. M. Química geral. São Paulo: Edgard Blücher, 2002. 676 p.

TABELA BRASILEIRA DE COMPOSIÇÃO DE ALIMENTOS. Campinas: NEPA-UNICAMP), 2004. 42 p. Disponível em:

<http://www.ime.unicamp.br/ teia/Eduardo/tab_bras_de _comp_de_alim_doc.pdf>. Acesso em: 15 jan. 2012. 